\title{
High Throughput Protein Expression and Purification. Methods and Protocols
}

\author{
(S. Doyle, ed., in Springer Protocols. Methods in Molecular Biology, Vol. 498 \\ (J. Walker, Serial ed.), Humana Press, N. J., 2009, 322 p., \$99)
}

DOI: $10.1134 / \mathrm{S} 0006297909080173$

The book consists 20 chapters, which cover methods in protein expression and purification summarized by leading experts in this area from USA, UK, and Switzerland.

Like other well known and very successful Protocols published for many years by Humana Press, this book includes methodical chapters with the details of most currently useful protocols, including various high throughput cloning schemes, protein expression analysis, and protein production. The special chapters of this book describe Escherichia coli, insect, and mammalian cells, as well as cell-free systems for the production of a wide variety of proteins, including glycoproteins and membrane proteins, in order to best represent strategies that create and exploit common features to enable simplified cloning, stable expression, and purification of proteins.

Each chapter presents the protocol of certain methods, step-by-step description starting with summary, introduction, materials, steps for realization of method on the bench, and a notes section for tips on troubleshooting and avoiding known pitfalls.

Numerous pictures in the text, a references list at the end of each chapter, and a subject index help better understand the presented materials.

The volume is true handbook for protein biochemists, molecular biologists, biotechnologists, and other researchers and technicians who are involved in the many applicable fields. 